\title{
NÓS: AMARRAS ENTRE PESQUISA, EXTENSÃO E ENSINO NO CAMPO DA LINGUAGEM
}

\author{
Otilia Lizete de Oliveira Martins Heinig*, Bethânia Coswig Zitzke**, \\ Maristela Pereira Fritzen ${ }^{* * *}$
}

\section{RESUMO}

As relações entre pesquisa, ensino e extensão mobilizaram a construção do artigo que visa refletir sobre as ações do Núcleo de Estudos Linguísticos em seus anos iniciais. A compreensão da linguagem como dialógica fundamentou a organização do Núcleo e de suas ações dentro da Universidade e da aproximação com a comunidade externa. Para este artigo, recortaram-se duas experiências que articulam pesquisa, ensino e extensão, apresentando sua gênese e resultados. Ambas focam o letramento e o desempenho do leitor, mas se diferenciam pela forma como foram concebidas e construídas. A primeira tem em seu processo inicial um projeto de pesquisa junto à comunidade escolar, a posterior publicação do trabalho e sua discussão e seu amadurecimento na interlocução com a comunidade escolar em forma de oficina. A outra foi articulada em sala de aula de futuros professores para que conhecessem a realidade educacional onde iriam estagiar, proporcionou ações durante a permanência na escola e se estendeu na pesquisa e divulgação de resultados junto às escolas. Não importa a via em que as ações acontecem nem o que vem primeiro: se pesquisa, ensino ou extensão. Os resultados e reflexões têm apontado muito mais para o diálogo entre universidade e comunidade escolar.

Palavras-chave: Extensão. Escola. Linguagem.

\section{ABSTRACT}

The relations between research, teaching and extension mobilized the construction of this article, which aims at reflecting about the actions of the Center of Linguistic Studies (Núcleo de Estudos Linguísticos) in its first years. The understanding of the dialogical nature language has guided the organization of the Center and its actions in the University as the same as the approach to the outside community. In order to organize the present article, we select two experiences which articulate research, teaching and extension, presenting also their genesis and results. Both focus literacy and the reader performance, but they differ in way they were planned and built. The first one involves, in its first planning steps, a research project developed in school community, followed by the publication of the work, its discussion and maturing in the discussion that took place in the school community as a workshop. The other one was articulated in the future teachers classroom context to let them know the educational reality in which they going to do their training. It enables actions during their stay at school and led to the research and disclosure of results in the schools. Independently from the way the actions took place and from what comes first, if research, teaching or extension, the results and reflections have been pointing mainly to the dialogue between the university and the school community.

Key words: University extension. School. Language.

\footnotetext{
* Professora titular do Departamento de Letras e do Programa de Mestrado em Educação e coordenadora do NEL — Núcleo de Estudos Linguísticos da Universidade Regional de Blumenau - FURB. Doutora em Letras pela Universidade Federal de Santa Catarina. Rua Antônio da Veiga, 140 - Bairro Victor Konder — CEP 89012-900 - Blumenau-SC. E-mail: otilia@furb.br. ** Professora titular do Departamento de Letras e membro do NEL. Mestre em Linguística pela Pontifícia Universidade Católica do Rio Grande do Sul - PUCRS. *** Professora titular do Departamento de Letras e do Programa de Mestrado em Educação e membro do NEL. Doutora em Linguística Aplicada pela Universidade Estadual de Campinas — Unicamp.
} 


\section{A LINGUAGEM QUE PERMITE DIÁLOGOS ENTRE PESQUISA, EXTENSÃO E ENSINO}

A intenção deste artigo é refletir sobre as experiências desenvolvidas no NEL (Núcleo de Estudos Linguísticos), um dos programas de extensão da Universidade Regional de Blumenau (FURB), criado em 2006. Atuando dentro de uma perspectiva de integração, o Núcleo agrega em suas ações professores do Departamento de Letras, do Programa de Mestrado em Educação, além de mestrandos, mestres, acadêmicos e egressos de licenciaturas.

O Núcleo tem como pressuposto que a extensão, considerada um "processo educativo, cultural e científico" (PNE citado por CALDERÓN \& SAMPAIO, 2002), é um espaço interessante na articulação entre ensino e pesquisa, pois aproxima a Universidade e a Sociedade. Podemos, então, metaforicamente, considerar a extensão como uma via de mão-dupla, especialmente por possibilitar a aproximação de mundo acadêmico do universo em que a prática acontece. Se pensarmos em termos de ensino, como no nosso Programa de Extensão, o olhar para o espaço do cotidiano da prática pedagógica e da produção textual, assim como da educação linguística, possibilita a aproximação entre professores e alunos que, ao discutirem a realidade externa, podem refletir sobre as maneiras como o conhecimento é construído. Como afirma o Plano Nacional de Extensão Universitária, "além de instrumentalizadora deste processo dialético de teoria/prática, a Extensão é um trabalho interdisciplinar que favorece a visão integrada do social" (BRASIL, 2001, p.5).

Especificamente focando o espaço da sala de aula, a extensão possibilita formação de um novo conceito, o de ir além das paredes que limitam, além do aluno idealizado e do conhecimento já determinado em cada plano de ensino. Ir a outros lugares sociais, circulando entre diferentes saberes, possibilita o contato com espaços "em que se realiza o processo histórico-social com suas múltiplas determinações, passando a expressar um conteúdo multi, inter e transdisciplinar, como exigência decorrente da própria prática” (op. cit., p. 6). No caso de nosso Programa, há a aproximação entre a universidade e a escola campo de estágio ${ }^{1}$, o que ocorreu como

1 Essa não era a meta inicial do projeto, mas esta orientação surgiu em decorrência de ações de extensão e da experiência de contato com a comunidade, tanto interna, quanto externa à Universidade. consequência das ações do Programa, mobilizando outras ações que não estavam contempladas no projeto inicial. Recorrendo ao Plano Nacional, percebe-se que este também é um espaço de extensão, pois o "estágio curricular é alçado como um dos instrumentos que viabilizam a extensão"(op. cit., p. 6).

A inserção no universo escolar permite compreender as relações entre os atores educacionais e aponta nichos de pesquisa que alimentam as ações da extensão que, por sua vez, instigam os pesquisadores a fim de analisarem os fenômenos educacionais. É uma relação quase infinita de reciprocidade. Essa relação torna os processos mais expressivos, uma vez que tanto pesquisa, como ensino e a própria extensão ganham novos significados e modificam percepções, geram reflexões e estabelecem posições e conceitos.

$\mathrm{Na}$ articulação entre teoria e prática, no âmbito do ensino da Língua Portuguesa, a concepção de gramática que se tem em foco, não raro, "é aquela que estuda apenas os fatos da língua padrão, na norma culta de uma língua, norma essa que se tornou oficial. [...] dita normas de bem falar e escrever, normas para a correta utilização oral e escrita do idioma [...]" (TRAVAGLIA, 2002, p. 30-1). O conhecimento da gramática é um dos objetivos da disciplina Língua Portuguesa nos Ensinos Médio e Fundamental, no entanto, o que se percebe é que os acadêmicos entram nos cursos superiores sem esse conhecimento, ou com apenas parte dele.

De acordo com Geraldi (1999), no inventário das deficiências que podem ser apontadas como resultados do que já nos habituamos a chamar de "crise do sistema educacional brasileiro”, ocupa lugar privilegiado o baixo nível de desempenho linguístico demonstrado por estudantes na utilização na língua, quer na modalidade oral, quer na modalidade escrita. Esse baixo nível gera dificuldades tanto no meio acadêmico quanto no meio profissional.

Diante desse quadro, tem-se questionado por que razões o ensino de Língua Portuguesa tem alcançado tantos insucessos. Nesse sentido, perguntamo-nos: como um programa de extensão, com foco justamente no ensino de Língua Portuguesa, pode trazer contribuições para a melhoria do ensino e da aprendizagem dos usuários da língua?

Algumas questões já têm sido levantadas por linguistas que apontam para a necessidade de se diferenciar um estudo que aborda a metalinguagem de uma 
língua, de um estudo que visa ao domínio desta, pois há uma diferença entre dominar as habilidades de uso da língua em situações concretas de interação e saber analisar uma língua dominando conceitos e metalinguagens a partir dos quais se fala sobre a língua. 0 que pode ser observado é que o ensino de Língua Portuguesa tem sido feito com base nos conceitos metalinguísticos, nas características estruturais, ou seja, o aluno sabe citar regras, classificar todos os tipos de sujeito, definir o que é um verbo ou uma preposição e, no entanto, não é capaz de construir um texto utilizando estas regras, não compreende que os textos devem ser adequados aos interlocutores e às formas de transmissão. Segundo Antunes (2008, p. 15), “tivemos, durante muito tempo, uma escola que favoreceu o mutismo, que obscureceu a função interativa da língua, que disseminou a ideia de uma quase irreversível incompetência linguística [...]”.

Outro problema percebido no ensino de Língua Portuguesa é a falta de clareza quanto às concepções de linguagem existentes. $\mathrm{O}$ ensino baseado na estrutura e metalinguagem da língua está amparado na concepção de que a linguagem é a expressão do pensamento, portanto, pessoas que não escrevem bem, não pensam bem.

0 que propomos, neste Programa, em resposta à problemática levantada, é que o ensino da gramática, da forma padronizada da língua, seja feito a partir da concepção de que a linguagem é uma forma de interação (BAKHTIN, 2003; 2004). Esta concepção não altera somente a forma de ensinar, mas sim o conteúdo a ser ensinado. Pois, por meio da linguagem, o sujeito que fala pratica ações que não conseguiria levar a cabo, a não ser falando; com ela o falante age sobre o ouvinte, constituindo compromissos e vínculos que não preexistiam à fala (GERALDI, 1999).

Outro foco pretendido são as reflexões sobre as práticas pedagógicas envolvendo a linguagem, pois, no que concerne ao trabalho com a língua portuguesa tanto no âmbito do uso social, do qual cada produtor de texto faz uso, como na transposição didática dos conhecimentos produzidos na academia, é preciso levar em conta as condições de produção dos sujeitos (DOLZ et al., 2004).

O programa procura, portanto, investigar e compreender a realidade vivenciada por educadores que atuam na área da linguagem e a partir dessas etapas, propor ações de ensino e extensão, para dar sentido às aulas de português, seguindo os questionamentos de Antunes (2008, p. 174):
As aulas de português, perguntamo-nos todos os dias: A favor de quem? A favor de quê? Se as pessoas não ficam mais capazes para - falando, lendo, escrevendo e ouvindo - atuarem socialmente na melhoria do mundo, pela construção de um novo discurso, de um novo sujeito, de uma nova sociedade, para que aulas de português?

Dentro dessa perspectiva, existe um grupo de pesquisa, anterior ao nosso Programa, que se reúne semanalmente. As investigações nele realizadas possibilitaram a organização no núcleo de extensão que, posteriormente, contou com os resultados das pesquisas para a construção da concepção de formação de professores e outros profissionais. Assim, o fundante é um viés dialógico, pois, "na Universidade reúnem-se, com estruturas e condições apropriadas (é o que é buscado, pelo menos!), pessoas capazes de, em diferentes áreas, produzir conhecimento com o consequente dever de torná-lo acessível” (FREIRE, 1997, p. 101).

Além do trabalho de pesquisa, a inserção nas escolas, através dos projetos de estágio, tem possibilitado uma leitura da realidade escolar e fomentado ações no âmbito do ensino na graduação e na escola pública. É possível, pois, ainda afirmar que "a extensão possibilita essa formação do profissional cidadão e se credencia cada vez mais junto à sociedade como espaço privilegiado de produção do conhecimento, significativo para a superação das desigualdades sociais existentes" (op. cit., p. 7).

\section{AS INTENÇÕES NO CAMPO DA EDUCAÇÃO LINGUÍSTICA: O CONTEXTO}

Considerando o inacabamento do ser humano (LÉON, 1977) e os constantes desafios contemporâneos, não se pode conceber a formação profissional do professor (e de outras áreas) como um produto com tempo e local determinados para que ele aconteça e finalize. A formação de professores e, em especial, a formação de professores da área de linguagem em sociedades grafocêntricas como a nossa, em que circulam textos que veiculam diferentes linguagens, precisa se estender para além do espaço-tempo previstos para a formação inicial exigida por lei para o exercício da profissão. 
Pesquisas na área da educação e da linguagem, com foco na formação de professores (ARROYO, 2000), apontam para o caráter permanente dessa formação (KLEIMAN, 2001). Antunes (2008, p. 174) chama a atenção para uma nova visão de professor, “[...] que se refaz, que redescobre, que reinventa, que revê suas concepções e atitudes, que não está "formado" e, portanto, redimensiona os seus saberes”. A formação continuada, com vistas a ampliar a compreensão do professor sobre os processos de ensinar, aprender, ler, escrever, pode se concretizar com a participação do professor em grupos de discussão, grupos de pesquisa, oficinas, eventos. 0 espaço da extensão na Universidade é central na concretização de tais ações de formação continuada, justamente por constituir ponto de encontro e de articulação entre a pesquisa produzida na esfera acadêmica e o ensino, para além dos limites da Universidade, legitimando seu compromisso social.

Essa interlocução pode ser promovida por meio de ações integradas e integradoras, isto é, por meio de ações que integrem teorias e conhecimentos construídos na esfera acadêmica com a prática educativa da sala de aula na educação básica, num exercício reflexivo contínuo, entre docentes, acadêmicos e professores, de revisão das práticas e apropriação crítica dos referenciais teóricos abordados nos documentos oficiais.

$\mathrm{Na}$ relação entre pesquisa e extensão, é difícil demarcar os limites entre uma e outra. Como afirma Amorim (2004, p. 11), "toda pesquisa só tem começo depois do fim. Dizendo melhor, é impossível saber quando e onde começa um processo de reflexão. Porém, uma vez terminado, é possível ressignificar o que veio antes e tentar ver indícios no que ainda não era o que passou a ser”. É neste viés que a aproximação entre pesquisaensino-extensão é compreendida em nosso Programa, levando em consideração que é necessário haver um “excedente de visão" (BAKHTIN, 2003) para analisar o fenômeno e também para propor ações que envolvam ou se desenvolvam a partir dele.

\section{AÇÕES NO CAMPO DA EDUCAÇÃO LINGUÍSTICA: AS APROXIMAÇÕES}

As ações desenvolvidas pelo NEL têm se concretizado a partir da integração e participação de mestrandos e mestres do Programa de Mestrado em Educação, de acadêmicos e egressos do curso de Letras e com a própria equipe permanente do NEL, formada por um professor coordenador, mais dois professores e dois bolsistas. Uma das ações no Núcleo tem sido a oferta de oficinas, por meio do Ciclo de Oficinas, que atendem acadêmicos das licenciaturas, de outras áreas, professores, egressos e comunidade em geral. Já foram realizados seis ciclos. As oficinas, ministradas aos sábados, são pensadas e organizadas a partir de trabalhos de pesquisa desenvolvidos por mestrandos e orientadores ou pelos acadêmicos do curso de Letras, orientados por seu professor. Essas pesquisas, muitas delas inspiradas nos questionamentos surgidos durante o estágio curricular, no caso dos acadêmicos, ou da própria prática docente, no caso dos mestrandos, são discutidas no Grupo de Pesquisa, citado anteriormente. 0 grupo tem potencializado o debate teórico em confronto com as práticas educativas e tem suscitado novos questionamentos e projetos de pesquisa.

Passamos a relatar duas dessas experiências de extensão, que concretizam de forma efetiva a interlocução entre pesquisa, ensino e extensão. Uma das oficinas oferecidas, denominada "Atualização sobre pesquisas e letramento", enfocou os cuidados nos exercícios de desempenho e avaliação de testes. A oficina promoveu uma reflexão a partir de dados do projeto de pesquisa "Interlocutores de crianças de 4 a . série em escolas públicas”, o qual foi desenvolvido em seis municípios catarinenses da região de abrangência da FURB e teve como objetivo identificar quem são os interlocutores das crianças nos seguintes aspectos: quem lê para elas; para quem elas leem; com quem elas conversam sobre o que leem. Os resultados apontaram um predomínio de interlocutores ligados aos meios familiares como a mãe, pai e irmãos, pouco aparece o professor. Os resultados foram publicados no artigo "O desempenho em leitura: uma investigação em escola pública”, apresentado na 29a. Reunião da Anped (2006), na qual foram dadas sugestões que o autor trouxe para a discussão e reflexão em sua oficina, oferecida a acadêmicos de licenciatura, mestrandos e professores interessados.

A avaliação da oficina pelos participantes aponta aspectos como a importância de cursos de atualização para a formação de professores, como pode ser visto nesses depoimentos de dois participantes: "Os conteúdos abordados foram ótimos. Penso que deveríamos ter mais tempo para falar e analisar esse assunto. A pesquisa realizada foi muito boa. E pude ter várias ideias 
para trabalhar com os pequenos no ensino fundamental". "Esses encontros são muito importantes para nossa formação. A troca de experiência é fundamental para enriquecer o nosso conhecimento". Esses dizeres se aproximam do pensamento de Calderón e Sampaio (2002, p. 108), para quem “a noção de extensão como prática acadêmica que visa assegurar a indissociabilidade das atividades de ensino e pesquisa, articulada com as demandas da sociedade", contribui para o cumprimento do compromisso social da Universidade.

Outra experiência de extensão foi a oficina "Testes de leitura”, que focalizou a construção de testes de leitura com aproximação com os parâmetros do PISA. Os referidos testes, elaborados por acadêmicos da 8 a. fase do curso de Letras, na disciplina de Língua Portuguesa, aplicados em escolas públicas, apontaram para os principais problemas de leitura, escrita e interpretação dos alunos. Os trabalhos, sob forma de relatório, foram entregues ao Núcleo e os resultados compilados e remetidos aos professores destas turmas e aos diretores das escolas envolvidas.

Essa interlocução permitiu a compreensão do espaço escolar por parte do futuro professor, bem como das políticas públicas de avaliação de desempenho em leitura. A escola, por sua vez, foi avaliada por um instrumento cujos textos estavam mais próximos de sua realidade. Os resultados dos testes alimentaram as atividades de estágio, mobilizando ações integradas e integradoras. Assim, podemos reafirmar que a extensão é uma via de mão-dupla,

que encontrará, na sociedade, a oportunidade da elaboração da práxis de um conhecimento acadêmico. No retorno à Universidade, docentes e discentes trarão o aprendizado que, submetido à reflexão teórica, será acrescido àquele conhecimento (CALDERÓN \& SAMPAIO, p. 106, 2002).

A oficina nasceu, assim, como uma resposta aos problemas de leitura constatados no teste, como uma forma de promover a reflexão com acadêmicos e, em especial, com os professores das escolas onde foram realizados os testes. A sua avaliação mostrou as implicações do tema trabalhado com a prática em sala de aula: "A oficina foi importante no sentido de que conhecemos um pouco mais sobre o mundo que abrange a leitura. Estou certo de que utilizarei muito do que aprendi hoje em sala de aula". "A oficina pôde me proporcionar mais conhecimento sobre a leitura, fazendo uma reflexão sobre a prática que utilizamos tanto na escola como em nossas leituras cotidianas". "Me motivou a ler mais e com mais qualidade".

As experiências relatadas mostram a extensão como um trabalho social, cooperativo e coparticipativo, no qual se engajam atores sociais do meio acadêmico e atores sociais da comunidade, neste caso, da esfera da educação, a partir da e sobre a realidade objetiva. Por meio dessas ações, o Núcleo de Estudos Linguísticos busca multiplicar as formas de tornar a comunidade interna e externa da Universidade beneficiárias da excelência do ensino, pesquisa e extensão desenvolvidos na FURB.

\section{ALGUMAS CONSIDERAÇÕES}

No início do artigo, nos propusemos a pensar sobre algumas experiências desenvolvidas no NEL. Desde sua concepção no ano de 1996, sempre houve o diálogo com a universidade e a primeira atitude foi uma pesquisa junto à comunidade acadêmica a respeito da necessidade de se propor um espaço para a produção textual. A reflexão foi sendo amadurecida durante anos de diálogos, às vezes solitários. Quando de seu início, em 2006, o Núcleo nasceu dentro da pesquisa que foi interagindo com as reflexões acerca do ensino e das extensões possíveis. Aqui, extensão vai para sua raiz etimológica, o que leva a compreender que a função do extensionista é de estender algo a alguém. Bastava definir o alguém e rediscutir o algo que tinha sido construído nas ações de ensino e pesquisa.

Muitos 'algos' nasceram durante os diálogos com a comunidade interna e externa, nosso 'alguém', mas, os limites do texto nos levaram a recortar duas experiências que possibilitaram a realimentação da nossa proposta inicial de articular, pela e na linguagem, o pesquisado, o vivido e o repartido. Os nós dessa amarração, construídos ao longo desses anos iniciais, encontraram fragilidades, mas elas alimentaram novas propostas, pois, como afirma Freire (1997, p. 107),

as relações entre Ciência, pesquisa e extensão universitária, dependem diretamente de aspectos importantes do trabalho científico: a gênese desse trabalho e a destinação de seus resultados. 0 ponto de partida do processo conhecer (a gênese dos problemas ou perguntas que desencadeiam esse 
processo) e o acesso que a sociedade tem aos resultados desse tipo de trabalho podem determinar em maior ou menor grau as relações entre Ciência e sociedade e, na medida em que a Universidade é a principal instituição responsável pela produção de conhecimento científico, podem também determinar as relações desta com a comunidade onde está localizada.

Dentro dessa compreensão dialógica de linguagem e extensão, o Programa continua refletindo sobre a frouxidão de seus nós e de como estender e captar conhecimentos produzidos em diferentes esferas de circulação dos saberes, sejam eles experienciais ou curriculares. É nesse difícil processo de articular o que parece tão simples teoricamente concebido que transitam as ações que circulam, pulam e pululam da pesquisa ao ensino e deste para a extensão, podendo também haver uma contramão.

AGRADECIMENT0: Agradecemos à Pró-Reitora de Pesquisa e Extensão da Universidade Regional de Blumenau por financiar o Núcleo de Estudos Linguísticos e tornar possível as ações relatadas neste artigo.

\section{REFERÊNCIAS BIBLIOGRÁFICAS}

AMORIM, M. O pesquisador e seu outro: Bakhtin nas Ciências Humanas. São Paulo. Musa Editora, 2004.

ANTUNES, I. Aula de português: encontro \& interação. 6. Ed. São Paulo: Parábola, 2008.

ARROYO, M. G. Ofício de mestre: imagens e auto-imagens. 7. Ed. Petrópolis, RJ: Vozes, 2000.

BAKHTIN. M. Estética da criação verbal. 4. Ed. São Paulo: Martins Fontes, 2003.

Marxismo e filosofia da linguagem: problemas fundamentais do método sociológico na ciência da linguagem. 11. Ed. São Paulo: Hucitec, 2004.

BRASIL. Plano Nacional de Extensão Universitária. Ed. Atualizada. 2001. Disponível em: <http://www.prce.ufsc.br/download/ pne.doc0 >. Acesso em: 29 jan. 2007.

CALDERÓN, A. I.; SAMPAIO, H. (org). Extensão Universitária: Ação comunitária em universidades. São Paulo: Olho d’Água, 2002.
DOLZ, J; SCHNEUWLY, B. et al. Gêneros orais e escritos na escola. Campinas : Mercado das Letras, 2004.

FREIRE, Paulo. Extensão ou comunicação? 10. Ed. Tradução de Rosisca Carcy de Oliveira. Rio de Janeiro: Paz e Terra, 1997.

GERALDI, J. W. Concepções de linguagem e ensino de Português. In: o texto na sala de aula. 2. Ed. São Paulo: Ática, 1999.

KLEIMAN, A. B. (org) A formação do professor: perspectivas da linguística aplicada. Campinas: Mercado de Letras, 2001.

LÉON, A. Psicopedagogia dos adultos. Tradução: Ivone de Andrade e Maria Elisa Mascaneras. São Paulo: Editora Nacional, Editora da USP, 1977.

SOUZA, O. O desempenho em leitura: uma investigação em escola pública. In: 29 Anped, 2006, Caxambu. 29a. reunião da Anped. Caxambu: MG, p, 2006. V. 1, p. 01-19.

TRAVAGLIA, Luiz Carlos. Gramática e interação. 8. Ed. São Paulo: Cortez, 2002. 